\title{
EDUCAÇÃO DO CAMPO: PERCURSOS HISTÓRICOS E NECESSIDADES NOS ASSENTAMENTOS DO MUNICÍPIO DE RORAINÓPOLIS, RORAIMA
}

\author{
Graciete Barros Silva iD1, Janaene Leandro de Souza iD2
}

Resumo: O presente artigo tem como finalidade discutir brevemente a Educação do Campo no contexto dos assentamentos no município de Rorainópolis, estado de Roraima, evidenciando uma das preocupações constantes que são as práticas e os desafios dos professores nas instituições escolares. Para a contextualização desta modalidade de educação, faremos uma investigação histórica em relação à educação rural, utilizando como artificio as legislações e resoluções que dão ênfase a essa temática. Utilizaremos como amparo teórico estudos de Ghedin, (2008; 2012), Molina (2006), entre outros, que dão ênfase aos estudos sobre a escola do campo, a formação continuada do professor, ressaltando 0 contexto e desafios existentes nos assentamentos. Diante disso, o presente estudo busca analisar os contextos e desafios vivenciados nas escolas dos assentamentos do município de Rorainópolis, tendo como base a formação dos professores deste município. A metodologia utilizada deu-se por meio de pesquisa bibliográfica e pesquisa de campo. Com base nos resultados obtidos, entende-se que este estudo contribui para o entendimento em relação às necessidades e desafios que os educadores do campo enfrentam diariamente, abrindo espaço para debates numa perspectiva de concretização de políticas públicas efetivas para as comunidades do campo nos assentamentos, não somente no município de Rorainópolis-Roraima, mas em todas as comunidades campesinas.

Palavras-chave: Educação campo; Formação de professores; Políticas públicas em Roraima.

\section{RURAL EDUCATION: HISTORICAL PATHS AND NEEDS IN THE SETTLEMENTS IN THE MUNICIPALITY OF RORAINÓPOLIS -RORAIMA}

Abstract: The purpose of this article is to briefly discuss Rural Education in the context of settlements in the Municipality of Rorainópolis, state of Roraima, highlighting one of the constant concerns that are the practices and challenges of teachers in school institutions. For the contextualization of this type of education, we will do a historical investigation in relation to rural education, using as artifice the laws and resolutions that emphasize this theme. We will use as theoretical support studies by Ghedin, (2008; 2012), Molina (2006), among others, that emphasize studies on the rural school, the continuing education of the teacher, highlighting the context and challenges existing in the settlements. Therefore, this study seeks to analyze the contexts and

${ }^{1}$ Mestra em Educação pela Universidade Estadual de Roraima (UERR). Professora efetiva da Educação Básica da Secretaria Municipal de Educação de Boa Vista, RR. E-mail: sgraciete.barros@gmail.com.

${ }^{2}$ Mestra em Educação pela Universidade Estadual de Roraima (UERR). E-mail: janaene_sousa@hotmail.com. 
challenges experienced in schools in the settlements of the municipality of Rorainópolis, based on the training of teachers in this municipality. The methodology used was carried out through bibliographic research and field research. Based on the results obtained, it is understood that this study contributes to the understanding in relation to the needs and challenges that rural educators face daily, opening space for debates with a view to implementing effective public policies for rural communities in the settlements, not only in the municipality of Rorainópolis $-R R$, but in all peasant communities.

Keywords: Education field; Teacher training; Public Policies in Roraima.

\section{Introdução}

Este tema foi escolhido devido ao contexto ao qual se localizam os assentamentos situados no sul do estado de Roraima, mas especificamente no município de Rorainópolis, na qual se pode dizer que uma das preocupações mais evidentes para o exercício desta modalidade de educação, acena em direção às práticas pedagógicas e aos desafios dos professores nas escolas do campo, portanto, o desencadeamento do presente estudo, surgiu mediante o interesse em compreender melhor as questões referentes à Educação do Campo, bem como as políticas públicas e os desafios a serem superados pelos professores dentro deste contexto educacional. Para a contextualização desde estudo, buscamos investigar por meio de fontes bibliográficas a breve história da Educação do Campo fazendo a correlação com a temática de estudo nos assentamentos no município de Rorainópolis - Roraima.

Neste sentido, a Educação do Campo é parte integrante das lutas dos movimentos sociais tais como as inquietações para a quebra da classe hegemônica, dando visibilidade à produção do conhecimento e, sobretudo dando voz e autonomia ao camponês, que sempre foi visto como inferior em relação à classe dominante. Podemos dizer que a Educação do Campo surge com uma lógica voltada para o desenvolvimento político, social, cultural e econômico dos cidadãos que vivem no campo, considerando os aspectos e diferenças históricas sociais.

Diante disso, a história das lutas da Educação do Campo no Brasil, ainda passa por amplos obstáculos e dificuldades, de modo que, tornam-se visíveis os embates que as escolas do campo sofrem devido às políticas de fechamento, advindas daqueles que deveriam proteger e garantir o direito ao acesso à educação, tomando como exemplo o descaso do poder público em manter essas escolas ativas.

Neste contexto, a Constituição Federal de 1988, no seu artigo 205 adverte que a educação é um direito de todos e dever do Estado e da Família e será promovida e incentivada com a colaboração da sociedade, visando o pleno desenvolvimento da pessoa, seu preparo para o exercício da cidadania e sua qualificação para o trabalho. 
Quanto ao que se refere à educação no meio rural, observamos que ela foi historicamente relegada a espaços marginais nos seus mais variados processos de elaboração e, sobretudo na implementação das políticas educacionais voltada para esta modalidade de educação. Sendo assim, a educação é direito de todos como mencionado acima, contudo, por muito tempo a grande maioria das pessoas que viviam no campo não usufruía desse direito, pois as políticas públicas para esta educação passavam despercebidas ou eram meros jogos de interesses.

Cabe ressalta que as escolas do campo no Brasil, ainda seguem o modelo de educação nos moldes da educação rural, assim como as escolas indígenas, quilombolas, ribeirinhas e outras, ou seja, podemos dizer que estas escolas não seguem os períodos agrícolas, tendo em vista que, ambas seguem o currículo das escolas da cidade conforme prevê a legislação LDB no 9394/96.

Desta feita, as perspectivas da Educação do Campo se apresentam como processo de formação fundamentada nas políticas públicas para o campo, pensada na interculturalidade e na sua multidimensionalidade territorial como premissa para a prática da cidadania. Portanto, a educação é uma política social que tem importante caráter econômico porque promove as condições políticas essenciais para o seu desenvolvimento (MOLINA, 2006, p.30). Diante disso, a Educação do Campo vem mostrando não somente instrutiva, mas, sobretudo formativa, esta deve ser vista não apenas como modalidade de ensino, mas também como uma política pública que garanta a população camponesa os mesmos direitos educacionais garantidos à população urbana, pois se percebe que no decorrer da história essa modalidade educacional sempre foi deixada em segundo plano, não havendo investimentos pelos representantes governamentais.

Logo, por meio deste trabalho propomos uma análise dos contextos e desafios vivenciados nas escolas dos assentamentos do município de Rorainópolis, na busca da valorização das realidades vivenciadas nestes assentamentos, com o intuito de abrir espaços para novos olhares sobre a questão da Educação do Campo em Roraima.

\section{Um breve histórico da educação do campo e suas perspectivas}

A história da Educação do Campo perpassa diferentes aspectos, tais como culturais, sociais e políticos, na qual se pode afirmar que esta modalidade de educação ganhou força devido às lutas sociais. Nesta premissa Arroyo (2004) adverte que a Educação do Campo se estabeleceu vinculada à luta dos movimentos sociais:

O movimento social no campo representa uma nova consciência do direito à terra, ao trabalho, à justiça, à igualdade, ao conhecimento, à cultura, a saúde e à educação. O conjunto de lutas e ações que os homens e mulheres do campo realizaram, os riscos que assumem, mostra quanto reconhecem sujeitos de direitos. (ARROYO, 2004, p.73).

Neste sentindo, a institucionalização da Educação do Campo é uma conquista histórica, tendo em vista que a educação oferecida pelo Estado ao 
povo camponês não considerava as suas particularidades, culturas e o contexto local. Diante disso, as lutas sociais manifestadas pelos movimentos camponeses na busca de melhorias e reconhecimento desta política frente ao sentimento de descasos até então vivenciados por estes povos podem ser considerados no ponto de vista de organização, um marco nas lutas para uma melhoria da qualidade de vida do povo do campo.

Vale mencionar que a história da Educação do Campo no Brasil ainda passa por grandes obstáculos e dificuldades, tendo em vista que o modelo da escola do campo segue o mesmo modelo da cidade, logo, percebe-se que este tipo de educação é tratado como política compensatória, uma vez que, este tipo de educação para as populações do campo é sempre trabalhado a partir de um currículo fundamentalmente urbano e na maioria das vezes, desarticulado das necessidades e da realidade do campo.

De acordo com a história, a educação sempre permaneceu presente em todas as constituições brasileiras, contudo, vale ressaltar que, mesmo o nosso país sendo basicamente agrário desde a sua formação, este tipo de educação não foi aludido nas escrituras constitucionais nos anos referentes a 1824 a 1891, vale mencionar que por muito tempo a Educação do Campo era vista como Educação Rural.

Assim sendo, Arroyo e Fernandes (1999) ressaltam que o termo "campo" é resultado de uma nomenclatura proclamada pelos movimentos sociais e foi adotada pelas instâncias governamentais e suas políticas públicas educacionais, sendo pronunciada em alguns universos acadêmicos por estudos rurais. Desta feita, percebe-se que a educação escolar no meio rural sempre esteve vinculada à educação "no" campo. Leite (1999) com seus estudos acerca da Educação Rural diz que

a sociedade brasileira somente despertou para a educação rural por ocasião do forte movimento migratório interno dos anos 1910/20, quando um grande número de rurícolas deixou o campo em busca das áreas onde se iniciava um processo de industrialização mais amplo. (LEITE,1999, p.28).

De acordo com Leite (1999), os povos do campo evidenciaram sua organização por meio de reivindicação de condições de trabalho, divisão da terra, de forma a garantir subsistência tendo como artifício a reforma agrária e consequentemente a delimitação territorial das terras.

Nesta conjuntura, nos anos de 1960 a Lei de Diretrizes e Bases da Educação (LDB 4024/61) consente a Educação Rural a cargo dos municípios, na qual diante desta denominação o educador Paulo Freire traz esses discursos traz várias contribuições para a educação popular, dando ênfase numa concepção de educação dialógica que valoriza a prática social dos sujeitos, como por exemplo, a Educação de Jovens e Adultos.

Com o advento da lei no 5.692/71, que traçou diretrizes para os níveis de primeiro e segundo grau, advertimos que em relação Educação do Campo não houve avanços, tendo em vista que nem se discutia nos discursos políticos e sociais o ensino para as escolas rurais. 
Neste contexto, com a aprovação da Constituição de 1988, a educação passa a ser destacada como "Educação um direito de todos", na qual, ressaltase que a educação deve ser direito de todo cidadão, logo, com o advento da Lei de Diretrizes e Bases da Educação Nacional - LDB 9394/96 no seu artigo 28 que trata da Educação do Campo percebe-se que esta modalidade de educação passa a conquistar seu espaço de direito nas agendas políticas, fortalecendo as lutas das organizações sociais que defendem uma Educação do Campo que expresse o trabalhador rural, enfatizando não somente seu lugar de trabalho, como também moradia, história, cultura, lazer e as mais diversas possibilidades.

Diante disso, a LDB em seu artigo 28 coloca os seguintes princípios para a educação do campo:

Na oferta da educação básica para a população rural, os sistemas de ensino proverão as adaptações necessárias à sua adequação, às peculiaridades da vida rural e de cada região, especialmente: Iconteúdos curriculares e metodologia apropriada às reais necessidades e interesses dos alunos da zona rural; II- organização escolar própria, incluindo a adequação do calendário escolar às fases do ciclo agrícola e às condições climáticas; III- adequação à natureza do trabalho na zona rural (BRASIL, 1996).

De acordo com a citação acima, a LDB no 9394/96 ao reconhecer a Educação do Campo, mesmo se referindo à Educação Rural, traz algumas adaptações necessárias ao currículo das escolas que estão localizadas no meio rural, contemplando a realidade e o contexto de vidas dos sujeitos que estão inseridos no campo.

Neste sentido, a Educação do Campo é tratada como Educação Rural na legislação brasileira, e seu significado incorporam diferentes espaços, tais como: espaços da floresta, da pecuária, das minas e da agricultura, na qual é evidente que esses espaços se transpõem ao acolher diferentes espaços tais como: pesqueiros, caiçaras, ribeirinhos e extrativistas. Sendo assim, o campo é mais que um limite não urbano, este por sua vez, é um campo de possibilidades que dinamizam a união dos indivíduos.

Cabe mencionar que as discussões sobre Educação do Campo foram fortalecidas a partir das experiências do Movimento dos Trabalhadores Rurais Sem- Terras (MST), em especial na organização dos espaços públicos, como por exemplo, o I Encontro Nacional de Educadores da Reforma Agrária (1997) e a I Conferência Nacional por uma Educação Básica do Campo (1998).

Nesta perspectiva, outra conquista ocasionada pelas lutas e organizações do povo do campo na construção da Educação do Campo, foi à elaboração das Diretrizes Operacionais para a Educação Básica nas Escolas do Campo que é o parecer no 6/2001 e a resolução no 1 /2002 do Conselho Nacional de Educação), que foi publicada no diário oficial da união no dia 9 de abril de 2002.

Este documento, na seção 1 , p.32, nos mostra que a identidade da escola do campo é determinada a partir dos sujeitos sociais a quem se destina como por exemplos agricultores, os assentados, os ribeirinhos, caiçaras, 
extrativistas, pescadores, indígenas, remanescentes de quilombos, enfim, todos os povos do campo brasileiro.

Desta forma, a história da educação do campo surgiu mediante a luta de homens e mulheres por uma educação que considere sua realidade social, econômica e política.

\section{Algumas considerações acerca dos assentamentos no município de Rorainópolis, Roraima}

De acordo com Durand (2016) existem diferenças entre a concepção de Educação Rural e do Campo. De modo que, a concepção Rural remete ao atraso no qual os sujeitos são vistos como aqueles que necessitam de assistência e proteção, estando alheios à sociedade e tendo a responsabilidade apenas de participar da produção e abastecimentos dos centros urbanos. Já a concepção de Educação do Campo valoriza a identidade dos sujeitos, sua cultura, conhecimento, valorização do local onde vivem, trabalham e se organizam, portanto neste estudo propomos refletir acerca da Educação do Campo.

Neste viés, os assentamentos nascem como consagração de luta, isto é, conquista de terra, que se distendem em novas perspectivas de produção, de renda, moradia e de condições dignas de vida e de trabalho, estes por sua vez, são constituídos no Brasil a partir da década de 1980.

Assim, a área deste estudo, nos remete ao município de Rorainópolis estado de Roraima, que se localizado ao sul do Estado de Roraima, interligado aos demais municípios e ao estado do Amazonas, através da BR 174. Tendo como limites: ao norte (município de Caracaraí), ao sul (Estado do Amazonas), ao leste (aos municípios de São Luiz e São João da Baliza) ao oeste (município de Caracaraí). Distante da capital do estado a $310 \mathrm{~km}$, com área territorial $33.740 \mathrm{~km}^{2}$, correspondendo a 14,99\% do estado, população de 24.466 habitantes, sendo na área urbana (10.114 hab.) e na área rural (14.352 hab.) (SEPLAN, 2007).

Neste contexto, a partir do descobrimento do Brasil em 1500, as terras brasileiras foram sendo gradativamente colonizadas, na qual, o direito a terra era feito de maneira desigual fazendo crescer a cada dia a desigualdade social, que se perpetua com uma nova roupagem até os dias atuais. Embora ainda haja uma má distribuição de terras no Brasil, muito se tem conquistado por meio de movimentos sociais com mencionado nas páginas anteriores, na qual, as populações rurais lutam pela sua igualdade de direito no que se alude à questão territorial.

Diante disso, a Reforma Agrária tenta suprir os anseios no que tange a segurança ao campesino que necessita de terra para a agricultura e o sustento de sua prole. Desta feita, na década de 1970 com a abertura da BR 174 que liga o Amazonas a Roraima e posteriormente à Venezuela, o Projeto de Assentamento Dirigido Anauá, nasce a partir da implantação de uma sede do Instituto Nacional de Colonização e Reforma Agraria - INCRA, com o objetivo de assentar os migrantes nordestinos. 
O projeto de assentamento foi criado em junho de 1979 sendo efetivado pelo INCRA assegurando as famílias de agricultores. Vale mencionar que o processo de construção do PAD Anauá levou alguns anos para se consolidar, passando por vários processos descritivos, determinando características, limites, área total e o mapeamento de todo o espaço.

Atualmente o Projeto de Assentamento Dirigido (PAD) Anauá, possui uma área de 221,8 mil hectares. Este assentamento foi desmembrado em 15 novas áreas, visando sua consolidação e emancipação das 3.052 famílias ali assentadas. Com isso, a área remanescente do PAD Anauá ficou com 21,8 mil hectares abrangendo o perímetro urbano da cidade de Rorainópolis, com capacidade para 293 famílias.

As 15 famílias remanescentes formaram para os Projetos de Assentamento (PAs) são elas: Sucuriju para 322 famílias; Pirá-Indirá para 114 famílias; Garapajá para 209 famílias; Monte Sinai para 223 famílias; Muriru para 180 famílias; Maguari para 115 famílias; Juari para 225 famílias; Jenipapo para 161 famílias; Curupira para 97 famílias; Campina para 413 famílias; Caju para 118 famílias; Ajuri para 199 famílias; Tepurema para 178 famílias e Tucumã com 344 parcelas.

De acordo, com os dados da Superintendência Regional de Roraima há 4 assentamentos em instalação. São eles: PA Jundiá, PA Equador, PA Ladeirão e PA Trairi. Dentre as famílias já assentadas há mais de dez anos, estimamos que haja aproximadamente 793 alunos em idade escolar. (INCRA: 2006).

O MST assim como outros movimentos, tem conseguido muitas conquistas no que tange ao direito a terra para muitos trabalhadores rurais em todo o Brasil, diante disso, cabe ressaltar que o assentamento PAD Anauá nasce como forma de organizar os trabalhadores rurais no campo e como meio de ocupação territorial organizado, na qual, o projeto é fortalecido pelas políticas de assentamento agrário. No entanto, em cada assentamentos foram construídas escolas para os filhos e filhas de assentados, com isso, o PRONERA começa a trabalhar na formação de professores por meio de parcerias com as universidades. Vale destacar que mesmo com tantos avanços nas legislações educacionais voltadas para Educação do Campo, a realidade das escolas para a população rural continua ainda muito precária, levando ao fechamento de muitas escolas.

\section{Práticas e desafios dos professores nos assentamentos no município de Rorainópolis, Roraima}

A sociedade em suas diferentes esferas sofre transformações na medida em que incorpora elementos e mudanças no seu caminhar, na sua trajetória, sendo necessário refletir sobre a educação do campo, em um sentido mais restrito, na formação dos educadores que atuam no campo. É neste sentido que percebemos o grande desafio frente à complexidade que envolve o ensino e a formação do educando.

Diante do exposto, o plano nacional de formação de educadores do campo fica responsável pela formação dos educadores do campo, contudo não existe uma definição exata de como deve ser a formação para este professor, 
apenas a certeza da necessidade de que este educador deve estar preparado para enfrentar as especificidades do campo. Assim, tratarmos do espaço rural e, particularmente, dos assentamentos, salta aos olhos as defasagens educacionais, por meio do acesso restrito aos níveis de ensino, pelas condições das escolas e pela acerca da formação dos educadores.

Neste sentido, uma educação preocupada com o processo de formação que respeita os saberes da experiência, que prioriza os conhecimentos como leitura do mundo, crítica com vistas a uma práxis transformadora deve necessariamente adotar uma concepção de currículo que contemple os saberes e a cultura dos sujeitos da ação educativa, por isso o currículo na educação do campo deve ser centrado na realidade dos educandos, a realidade camponesa, como ponto de partida e base do currículo sendo, portanto, desenvolvido através de temas geradores, assim entendidos pelo MST (DOSSIÊ MST ESCOLA, 2005, p.55).

Portanto, na percepção da Educação do Campo, o educador tem um conceito mais abrangente e seu campo de atuação é muito mais diversificado, como adverte Caldart (1997):

Construir a Educação do Campo significa formar educadores e educadoras do campo para atuação em diferentes espaços educativos. $\mathrm{E}$ se defendemos uma formação específica é porque entendemos que boa parte deste ideário que estamos construindo é algo novo em nossa própria cultura. Há uma nova identidade de educador que precisa ser cultivada, ao mesmo tempo em que há toda uma tradição pedagógica e um acúmulo de conhecimentos sobre a arte de educar que precisa ser recuperada e trabalhada desde esta intencionalidade educativa da Educação do Campo. (CALDART, 1997, p.15).

Assim sendo, após conferências, debates e muitas lutas, para a melhoria das políticas públicas à educação do campo, vislumbra-se hoje um grande progresso nesta área. $\mathrm{Em}$ se tratando das necessidades dos professores dos assentamentos do PAD Anauá, observamos que estes gostariam muito de ter cursos voltados para formação continuada. Vale mencionar que diversos programas $e$, principalmente o PRONERA vem formando muitos professores, respondendo os anseios das comunidades campesinas e assentamentos, mas infelizmente a classe hegemônica insiste em uma visão dicotomizada em relação a formação dos professores do campo.

Neste sentido, tomam-se como exemplo duas ações voltadas para a formação continuada dos professores do campo, todas em parceria com o Instituto Nacional da Reforma Agrária - INCRA e de universidades das quais cito: Universidade Estadual do Amazonas - UEA, com curso de formação de professores do campo já finalizado e a Universidade Estadual de Roraima UERR com especialização em educação do campo também já concluída no ano de 2015.

Todavia, o Plano Nacional de Educação - PNE, embasado na Lei de Diretrizes e Bases da Educação Nacional e demais dispositiva, trabalha na perspectiva da formação de um professor reflexivo para atuarem também nas escolas do campo com vistas a sua inserção no meio social com igualdade. Diante disso, a educação do campo é identificada por meio da valorização da 
tarefa dos educadores, de modo que a escola passa a se tornar um local de reflexão e de projetos culturalmente definidos.

Diante dessa conjuntura, os referenciais para a política nacional de educação do campo, BRASIL (2003) adverte que "a educação recria o campo porque através dela se renova os valores e as atitudes, os conhecimentos e as práticas de pertença a terra", ou seja, o campo é concebido como um espaço de construção e reconstrução de saberes onde as vivências devem ser pensadas como parte fundamental do processo educativo e, principalmente da formação dos professores do campo.

Neste contexto, em suas especificidades observa-se ainda que a falta da efetivação das políticas públicas ainda é um entrave quando se trata das escolas do campo, que acaba não dando condições para o trabalho dos professores nas próprias escolas campo, mas especificamente dos assentamentos. São escolas pequenas que na sua maioria comporta um único professor que ministra as disciplinas do currículo no modelo multisseriado. Esse é um dos problemas de descrédito da educação do campo, pois os professores têm que trabalhar com duas ou quatro turmas simultaneamente e acaba não desempenhando suas funções com a qualidade exigida.

De modo geral, podemos dizer que as escolas que fazem parte dos assentamentos do município de Rorainópolis a grande maioria encontra-se em péssimo estado de conservação ou já não existem, levando muitos alunos a estudarem na sede do município. Outro fator agravante é a falta de professores para atuarem nestas escolas, que devido à sua localização e modelo de ensino não querem trabalhar com este público. Então, devemos pensar na formação de professores que já residam dentro do próprio campo/assentamento.

Todos esses fatores citados anteriormente estão atrelados à diminuição da população do campo e ao acesso a todas as escolas, considerando principalmente as épocas de chuvas que podem variar a cada estação. Ainda há que considerar outro fator dentro deste contexto que é o calendário escolar, na qual deve adequar-se as estações chuvosas à colheita, produto que quase sempre é destinado aos comércios do município e ao sustento da prole.

Neste contexto Gracindo (2006) ressalta que:

A escola do campo, o sistema educativo do campo se afirmará na medida em que se entrelaçarem com a própria organização dos povos do campo, com relações de proximidade inerentes à produção camponesa - a vizinhança, as famílias, os grupos, enraizar-se e aproximar as formas de vida centrada no grupo, na articulação entre as formas de produzir a vida (GRACINDO,2006, p.36).

Logo, as necessidades das escolas do campo ainda são muitas e à medida que as políticas públicas vão caminhando no sentido de saná-las ou minimizá-las devem ter em mente que as mudanças ocorrem para melhorar as condições de ensino e não dos índices da qualidade nos gráficos que tanto se busca.

Portanto, a educação nas escolas dos assentamentos deve vivenciar também a realidade dos alunos uma vez que suas maiores necessidades são a 
valorização de seus conhecimentos, dando-Ihes confiança no dia a dia e o respeito ao seu espaço, logo, a valorização da escola e do professor por meio de práticas pedagógicas voltadas para o campo torna-se fundamental para se desvincular dos currículos conferidos pela cidade promovendo a valorização das experiências campesinas assim como a oportunidade propiciar formação continuada por meio de cursos técnicos e consequentemente promover 0 acesso a universidades.

\section{Metodologia}

Este trabalho fundamenta-se em uma abordagem qualitativa. Conforme descreve Minayo (2010), o método qualitativo pode ser definido como:

[...] é o que se aplica ao estudo da história, das relações, das representações, das crenças, das percepções e das opiniões, produtos das interpretações que os humanos fazem a respeito de como vivem, constroem seus artefatos e a si mesmos, sentem e pensam. As abordagens qualitativas se conformam melhor a investigações de grupos e segmentos delimitados e focalizados, de histórias sociais sob a ótica dos atores, de relações e para análises de discursos e de documentos (MINAYO, 2010, p. 57).

Os procedimentos técnicos que foram adotados para a coleta de dados na referente pesquisa consistiu em: Pesquisa bibliográfica e pesquisa de campo. Quanto às finalidades esta será de natureza descritiva, que, segundo Gil (2008) tem como objetivo primordial a descrição das características de determinada população ou fenômeno e tem como uma de suas características a utilização de técnicas padronizadas de coleta de dados. (GIL, 2008, p. 42).

Assim sendo, pesquisa bibliográfica é uma estratégia que busca explicar um problema por meio de estudos, teorias, descobertas, divulgados em diferentes fontes: livros, revistas, artigos, enciclopédias, veículos eletrônicos de informações etc. A utilização dessa estratégia de pesquisa consiste no conhecimento e análise de um conjunto de contribuições científicas e teóricas acerca de um tema que desejamos compreender (GIL, 2008).

Silva e Karkotli (2011), a pesquisa bibliográfica é o levantamento de toda a bibliografia já publicada, em forma de livros, revistas, publicações avulsas e imprensa escrita, cujo sua finalidade é:

Fazer com que o pesquisador entre em contato direto com todo o material escrito sobre um determinado assunto, auxiliando o cientista na análise de suas pesquisas ou na manipulação de suas informações. Ela pode ser considerada como o primeiro passo de toda a pesquisa científica (SILVA E KARKOTLI, 2011, p.12).

Assim sendo, a pesquisa bibliográfica foi essencial para a elaboração desse estudo, pois possibilitou a obtenção de informações acerca do objeto de estudo, trazendo autores que abordam sobre a Educação do Campo.

Já a pesquisa de campo contribuiu na coleta de dados, através de visitas "in loco" nos assentamentos no Município de Rorainópolis-Roraima. Vergara (2004) comenta que a pesquisa de campo é feita no local onde "ocorre 
ou ocorreu um determinado fenômeno, havendo elementos que permitam explicá-lo, sendo os dados coletados por intermédio de entrevistas, questionários, testes ou observação participativa" (VERGARA 2004, p.47).

Como método de análise utilizou-se a análise de conteúdo fundamentado em Bardin (2010), que tem um caráter essencialmente qualitativo.

\section{Considerações finais}

A história confirma que as políticas educacionais voltadas para a realidade camponesa brasileira são construídas a partir de um contexto bem delineado das intenções políticas que regem o fortalecimento da estrutura social e produtiva no Brasil, no que se refere à formação humana dentro do processo produtivo, de modo a viabilizar as prioridades do capital.

Diante disso, podemos ressaltar que a Educação no Campo sempre teve seus dilemas como a discriminação das pessoas que ali vivem e na maioria das vezes exclusão social acaba gerando uma serie de discriminação e preconceito, na qual na maioria das vezes os agricultores são tidos como mão de obra barata para os grandes fazendeiros gerando a desvalorização do seu trabalho. A educação é um direito de todo e qualquer indivíduo, e deve ser garantida pelo poder público a toda população independente desta residir em um meio rural ou urbano, sendo assim, temos garantido em lei aos povos do campo o aceso a educação, mas, infelizmente na prática essa educação acaba não acontecendo, tendo em vista que a grande maioria das escolas dos assentamentos no município de Rorainópolis encontram-se fechadas ou em péssima condição.

Outro fator que é de suma importância nas escolas do campo é a concretização de um currículo que se aproxime da realidade dos sujeitos que vivem no campo, a fim de se tornar um local de produção e reprodução de dinâmicas capazes de atender as necessidades locais, mas infelizmente esse currículo ainda não existe nestas escolas tendo em vista que o currículo utilizado em um currículo das escolas da cidade.

Desta feita, a formação de professores para atuarem nos assentamentos tem sido uma das nossas preocupações em razão da nossa atuação na educação do campo. Portanto, as práticas e desafios dos educadores do campo estão passando por grandes dilemas, na qual, pode-se dizer que os problemas frequentes estão relacionados com o cotidiano, uma vez que há dificuldades tais: a escassez de materiais, péssimas condições das escolas, e a ausência de formação continuada aos educadores.

Neste sentido, podemos dizer que é necessário o desenvolvimento de projetos que visem a qualidades das práxis educativas nos assentamentos ora citados na qual poderá contribuir para a elaboração de políticas públicas, como a formação do professor do campo e consequentemente a possibilidade da retomada da educação nos assentamentos do PAD Anauá nas escolas que se encontram fechadas.

Sendo assim, a problemática da educação do campo reside, não apenas na ausência de um projeto educativo adequado à realidade, mas exige algo 
ainda maior que é um projeto de integração que possibilite aos que moram no campo, alternativas para o crescimento e desenvolvimento de forma sustentável, uma vez que, até então, "os inúmeros investimentos, projetos, problemas e recursos destinados à educação sempre tiveram como finalidades servir ao processo de produção e reprodução de relações econômicas e sociais que contribuíram de maneira acentuada para a falência da educação no campo" como adverte Arroyo (2004).

Desta feita, é necessário o entendimento em relação às necessidades e os desafios que os educadores do campo enfrentam todos os dias, sendo necessária a concretização de políticas públicas efetivas para as comunidades do campo nos assentamentos.

\section{REFERÊNCIAS}

ARROYO, Miguel Gonzalez; CALDART, Roseli Salete; MOLINA, Mônica Castagna (Orgs.). Por uma Educação do Campo. Petrópolis: Vozes, 2004.

BARBOSA Raquel Lazzari Leite. Formação de educadores: desafios e perspectivas. São Paulo: Editora UNESP, 2003.

BARDIN, Laurence. Análise de conteúdo. 4ª. Ed. Lisboa: Edições70, 2010.

BRASIL. Grupo permanente de trabalho de educação do campo. Referências para uma política nacional de educação do campo: caderno de subsídios. Ministério da Educação, Brasília 2003.

BRASIL, Ministério da Educação e Cultura. Diretrizes operacionais para a educação básica nas escolas do campo. Resolução CNE/CEB No 1. Brasília: 2002.

BRASIL, Ministério da Educação e Cultura. Lei de Diretrizes e Bases da Educação Brasileira - LDB de 20 de dezembro de 1996.

BRASIL, Ministério da Educação e Cultura. Plano Nacional de Educação. Brasília - DF. Congresso Nacional 1998.

CALDART, Roseli Salete. Pedagogia do Movimento Sem Terra: escola é mais do que escola. Petrópolis, RJ: Vozes, 1997.

DURAND, Jean Pierre. A Sociologia de Marx. Petrópolis: Vozes, 2016. (Coleção Sociologia: Pontos de Referência).

EAGLETON Terry. Ideia de cultura. Atividades Editoriais, Ltda. Lisboa, 2003.

FERREIRA Andrea Tereza Brito, ALBUQUERQUE Eliana Borges Correia de, LEAL Telma Ferraz. Formação continuada de professores. $1^{\mathrm{a}}$. Ed. Belo Horizonte: Autêntica, 2007. 
FERNANDES Bernardo Mançano et al.; (Org.), SANTOS Clarice Aparecida dos. Educação do Campo: campo - políticas públicas - educação. Brasília: Incra; MDA, 2008.

FONSECA, Rosa Maria; MOURÃO, Arminda Rachel Botelho. A educação no campo: uma realidade construída historicamente. In: GHEDIN, Evandro (Org). O voo da borboleta. Manaus: Ed. Valer, 2008.

FREIRE, Paulo. Pedagogia da autonomia: saberes necessários à prática educativa. São Paulo: Paz e Terra, 1996. (Coleção Leitura)

GIL, Antônio Carlos. Como elaborar projetos de pesquisa. $4^{a}$. Ed. São Paulo: Atlas, 2008.

GRACINDO Regina Vinhaes et. al. Conselho Escolar e a educação do campo - Brasília: Ministério da Educação, Secretaria de Educação Básica, 2006. Disponível: http://portalantigo.incra.gov.br. Acesso em: 20 ago. 2017.

GHEDIN, Evandro (Org.). Educação do Campo: epistemologias e práticas. São Paulo: Cortez, 2012.

LEITE, Sérgio Celani. Escola rural: urbanização e políticas educacionais. São Paulo: Cortez, 1999.

MINAYO, Maria Cecília de Sousa. O desafio do conhecimento: pesquisa qualitativa em saúde. São Paulo-Rio de Janeiro: HUCITEC-ABRASCO, 2010.

MOVIMENTO DOS TRABALHADORES RURAIS SEM TERRA. Dossiê MST escola. Documentos e Estudos 1990 - 2001. ITERRA, 2005. 